\title{
Apresentação: Precisamos de um “método" para ler os clássicos da política?
}

Esta edição da revista TEMPO DA CIÊNCIA publica um conjunto de artigos que permite vislumbrar como o envolvimento com a pesquisa - além do ensino e da extensão - são fundamentais para a formação universitária. Os trabalhos apresentados foram motivados ou influenciados por um tipo de prática que contribui para formar cientistas sociais capazes de realizar pesquisas teóricas desde a graduação, que podem ser aprofundadas no mestrado e doutorado. Mostram que é possível desenvolver a capacidade de reflexão a respeito da realidade aproveitando o que já foi pensando e sistematizado desde o surgimento da teoria política: em Atenas, sob a influência da principal experiência de democracia e a única que pode ser chamada de "direta", embora também tenha sido limitada por diversos fatores que podem ser melhor conhecidos por meio de uma contextualização eficaz.

Os artigos que compõem o dossiê Contextualismo Social foram escritos tendo como base estudos realizados pelo grupo de estudos de teoria política ligado ao Grupo de Pesquisa Democracia e Desenvolvimento (GPDD) com o objetivo de elaborar um conceito de democracia capaz de desafiar a visão dominante que se contenta com uma definição mínima, formal, eleitoral e procedimental de democracia - bem como tentativas de chamar de democráticas formas "autoritárias" de governo que incluem alguma participação popular. A proposta foi reafirmar a importância da liberdade e incluir a igualdade substantiva como requisito para usar o termo democracia, tal como aparece no artigo $A$ construção do conceito moderno de democracia: versão inicial de um projeto de pesquisa, publicado na revista Tempo da Ciência (2016, v. 23, n. 45), escrito em parceria por mim e pelos professores Geraldo Magella Neres e Osmir Drombowski (2016).

Com esse objetivo passamos a reler as principais obras de teoria política que analisam a experiência democrática ateniense, visando entender como foi possível ao povo participar diretamente das decisões da pólis grega e por que depois isso não se repetiu. A formação na área de Ciência Política costuma ser pautada pela leitura direta de autores clássicos e seus comentadores renomados, reproduzindo a visão dominante a respeito da experiência de participação direta do povo (demos) em Atenas, apresentada por Sócrates, Platão e Aristóteles e repetida por autores modernos e contemporâneos. Porém, ao termos contato com as problematizações de Neal Wood e Ellen Meiksins Wood - os principais questionadores do viés antidemocrático gerado pelos clássicos gregos e divulgado pelos seus tradutores e comentadores mais famosos - conhecemos os resultados de uma releitura contextualizada das obras clássicas, que explicita o engajamento político de tais autores na luta política do período em que viveram.

\footnotetext{
${ }^{1}$ Graduada em Ciências Sociais (UFPR), mestra e doutora em Ciência Política (USP), professora de Ciência Política e Relações Internacionais (UNIOESTE, Campus de Toledo).
} 
Ao analisar a proposta de Neal Wood (1922-2003) de realizar uma história social da teoria política por meio da contextualização social de autores e obras - sobretudo tal como foi exposta no artigo escrito por ele em 1978, publicado na revista Political Theory - passamos a discutir as descobertas dele e de sua parceira no empreendimento, Ellen Meiksins Wood (1942-2016), que reinterpreta a maioria dos autores clássicos da política desde a antiguidade grega até a modernidade ${ }^{2}$. Ao entender o método e seus resultados práticos, passamos a nos questionar em que medida o "modo" como escolhemos "ler" uma obra clássica de teoria política poderia efetivamente fazer diferença para a compreensão do significado dos textos. Apresentamos aqui alguns dos resultados das nossas pesquisas - que iniciaram nos encontros do grupo de estudo vinculado ao grupo de pesquisa e continuaram por meio de orientações de iniciações científicas, trabalhos de conclusão de curso de graduação e dissertações de mestrado.

No primeiro artigo - Como realizar a contextualização social das obras clássicas da política? - apresento uma atualização das tabelas que organizei para facilitar a aplicação do método elaborado pela parceria entre Neal Wood e Ellen Meiksins Wood - pois já tinha publicado uma primeira versão nos Anais do Simpósio Paranaense de Ciências Sociais (realizado em 2016) ${ }^{3}$. Aqui, apresento brevemente porque o contextualismo social parece ser o método mais adequado para estudar os clássicos da política - quando comparado ao textualismo de Leo Strauss e ao contextualismo linguístico de Quentin Skinner - e explicito como seria um passo a passo para efetivamente aplicar o método. O objetivo foi criar um guia para as pesquisas do Grupo de Pesquisa Democracia e Desenvolvimento, pois pensávamos em realizar uma ampla contextualização de autores e autoras que de alguma forma produziram obras relevantes a respeito da democracia, desde Atenas até as modernas democracias eleitorais.

Para facilitar a aplicação da proposta do contextualismo social, elaborei sete tabelas com questões que orientam a pesquisa em quatro etapas: (I) Primeira: contexto social e biografia (Tabela 1: Contexto social em que o autor escreveu a obra em análise; e Tabela 2: Biografia); (II) Segunda: ideal humano (Tabela 3: Ideal Humano e Tabela 4: Prescrições para realização do ideal humano); (III) Terceira: alcance das ideias dos clássicos (Tabela 5: Delimitar a especificidade histórica das ideias do teórico); (IV) Quarta: ideologia versus teoria política (Tabela 6: O Teórico da Política (diferente dos ideólogos) e Tabela 7: Quais os destinatários das ideias do autor?). As tabelas (sobretudo na primeira versão de 2016) foram utilizadas para guiar algumas pesquisas que orientei (no mestrado em Ciências Sociais) e sua aplicação pode ser analisada a partir dos resultados apresentados nesse dossiê em dois artigos - o de Juliane Helanski (2017), sobre Bento Espinosa; e o de Francioli Bagatin (2018) - sobre Emma Goldman.

\footnotetext{
${ }^{2}$ Em obras como: Class Ideology and Ancient Political Theory: Socrates, Plato, and Aristotle in Social Context (1978); Citizens to lords A social history of Western Political Thought from Antiquity to the Middle Ages (2008) e Liberty and Property: a Social History of Western Political Thought from Renaissance to Enlightenment (2012).

${ }^{3}$ Uma primeira versão das tabelas está em: SILVA, Vania Sandeleia Vaz da Silva. O contextualismo social de Neal Wood e Ellen Meiksins Wood: uma introdução. Anais do V Simpósio Paranaense de Ciências Sociais. Disponível em: http://200.201.88.178/simposiocienciassociais/arquivos anais / ANAIS $\% 20$ SIMPOSIO $\% 20$ final.pdf\#page=86\&zoom=10 0,109,269 Acesso em: 05 out. 2019.
} 
O segundo artigo - O contraponto de Ellen Meiksins Wood ao viés antidemocrático de Sócrates, Platão e Aristóteles - apresenta um resumo do resultado da pesquisa realizada por Ellis Fernanda Lacowicz que resultou na sua dissertação de mestrado (LACOWICZ, 2018). A autora mostra como o método em questão - o contextualismo social - permitiu a Ellen Meiksins Wood explicitar o quanto o viés antidemocrático dos clássicos da política pode ser entendido como fruto de um engajamento político no conflito do período em que produziram suas interpretações sobre a democracia. No caso, o argumento apresentado por Ellen Wood na obra Democracia contra capitalismo (2010) é discutido a partir de exemplos que ilustram a forma como uma visão partidária - elaborada por Sócrates, Platão e Aristóteles - foi tratada como se fosse "neutra" ou "descritiva" com relação à experiência ateniense e o quanto isso gerou consequências para a visão do mainstream da Ciência Política, repetida por autores canônicos como Norberto Bobbio.

O artigo de Ellis Fernanda Lacowicz permite entender a importância da utilização do método do contextualismo social para reinterpretar alguns argumentos que costumamos ver repetidos em várias obras consideradas como referência a respeito da democracia ateniense. Assim como a leitura de sua dissertação, o artigo pode reorientar a escolha de bibliografia para as disciplinas de Ciência Política na medida em que mostra que muitas afirmações que considerávamos incontestáveis são, de acordo com a releitura proposta por Ellen Meiksins Wood e Neal Wood, a repetição de um viés de "classe" que gerou diversos preconceitos contra as pessoas que realmente produzem - os produtores diretos ou trabalhadores - quando desejam participar do governo. Dizer que existem provas de que o "povo" não tem condições de participar da política porque em Atenas sua participação esteve relacionada com a escravidão e gerou a ruína da pólis é uma das falácias, consequência do viés antidemocrático dos clássicos.

O terceiro artigo - O contexto social da obra de Ellen Meiksins Wood e a busca por sistematizar uma teoria de classes - escrito por Jefferson Ferreira do Nascimento com base em sua dissertação de mestrado (NASCIMENTO, 2018), pretende resgatar a proposta de Ellen Meiksins Wood sobre a necessidade de sistematizar uma teoria sobre classes que contribua para uma renovação do materialismo histórico. Um dos objetivos da autora foi contribuir para a luta por uma democracia substantiva que permitisse que o poder do povo alcançasse não apenas o que seria possível sob a democracia representativa (votar). Trata-se de construir uma possibilidade real de isegoria, de autodeterminação dos produtores, mediante um tipo de "livre" associação. Para tanto, seria essencial a organização da classe operária, como sujeito histórico, para levar adiante a luta de classes contra os “apropriadores” que são respaldados pelo poder do Estado, independente de qual seja a forma de governo sob o capitalismo - chamada de democrática ou não.

O artigo de Jefferson Ferreira do Nascimento é fundamental porque realiza uma contextualização social de Ellen Meiksins Wood - resgata dados biográficos, analisa o ideal humano e o contexto social da produção da autora para compreender a especificidade histórica das suas ideias - tal como o método do contextualismo social propõe que se faça com qualquer teórico ou teórica da política. Depois de situar autora e obra no contexto, cabe explicar o motivo pelo qual ela entende que a concepção de classe que 
atende ao empreendimento seria aquela formulada pelo historiador britânico Edward Palmer Thompson. Esse artigo é especialmente interessante porque aplica o método para analisar alguém que contribuiu na sua elaboração e aplicação, trazendo dados interessantes de sua trajetória, vida e obra, e, também, abordando um dos temas mais importantes para ela, dialogando com um dos autores que mais respeitou na construção de seu próprio pensamento a forma de interpretar o marxismo.

O quarto artigo - O conceito de 'moderno Principe': uma leitura contextualizada dos Cadernos do cárcere -, escrito pelo professor Geraldo Magella Neres, aplica a perspectiva metodológica do contextualismo social para realizar uma nova compreensão do conceito gramsciano de "moderno Príncipe", a qual, como a maioria dos conceitos elaborados por Gramsci nos Cadernos do cárcere, continua gerando várias polêmicas interpretativas. De acordo com o autor, a principal causa dessas controvérsias "exegéticas" deve-se ao caráter fragmentário dos escritos carcerários e, também, ao método de trabalho empregado por Gramsci. Para Geraldo Magella Neres, existiriam três vantagens na aplicação do contextualismo social para entender a teoria política de Gramsci. A primeira é a possibilidade de apreender a união entre teoria e prática na elaboração de qualquer teoria política, inclusive a gramsciana, explicitando a ligação entre o Gramsci "militante” com o Gramsci "teórico" ou dos escritos pré-carcerários e os carcerários.

A segunda vantagem está no fato de que o contextualismo social, de acordo com Geraldo Magella Neres, permite identificar uma "continuidade orgânica na elaboração da teoria do partido na reflexão de Gramsci” e torna possível estabelecer "uma relação de manutenção/superação entre as concepções de partido presentes nas "Teses de Lyon" e aquelas desenvolvidas nos Cadernos do cárcere". A terceira vantagem seria que o contextualismo social permitiria também "identificar a proposição do 'moderno Príncipe' como o desenvolvimento mais avançado de uma teoria do partido que já vinha sendo concebida por Gramsci desde o período anterior à prisão". Partindo dessas proposições e recorrendo às novas categorias políticas elaboradas por Gramsci no cárcere, o autor afirma que a teoria gramsciana do partido pode ser apresentada de forma sistematizada, facilitando sua compreensão mesmo por parte de pessoas não especializadas no tema ${ }^{4}$. Portanto, trata-se de uma exploração das vantagens da utilização do contextualismo social no caso de um autor que já é considerado "engajado" nas lutas do seu tempo.

O quinto artigo - Reflexões sobre a interpretação marxista da teoria política de Bento Espinosa feita por Ellen Meiksins Wood - traz parte das reflexões realizadas por Juliane Helanski durante a pesquisa que resultou em sua dissertação de mestrado (HELANSKI, 2017). A autora discute as principais características teórico-metodológicas do contextualismo social por meio de uma reflexão analítica da interpretação marxista que Ellen Meiksins Wood realizou da teoria política do filósofo Bento Espinosa. Representa uma

\footnotetext{
${ }_{4}^{4}$ Geraldo Magella Neres vem estudando o pensamento de Antonio Gramsci desde sua formação acadêmica (veja-se, por exemplo, NERES, Geraldo Magella. Gramsci e o "moderno Príncipe”: a teoria do partido nos Cadernos do cárcere. São Paulo: Cultura Acadêmica, 2012) e foi também a pessoa responsável por trazer como proposta de metodologia de estudo da teoria política a história social da teoria política (iniciando pelo artigo de Neal Wood, de 1978), tendo conduzido diversas seções do grupo de estudos de teoria política ligado ao grupo de pesquisa Democracia e Desenvolvimento, do qual fizeram parte a maioria das autoras e autores desse dossiê. Foi quem sugeriu que contextualismo social era uma denominação mais precisa para o método.
} 
verificação sistemática do quanto o método pode ser aplicado, pois, por meio da utilização da primeira versão das tabelas (SILVA, 2016), discutiu o quanto Ellen Meiksins Wood, na sua contextualização social de Bento Espinosa, efetivamente respondeu aos questionamentos levantados por Neal Wood (1978) e avançados por ela (WOOD, 2008, 2012). Desse modo, foi possível exemplificar, de forma didática, quais as vantagens e limites da aplicação do contextualismo social para uma melhor compreensão e explicação do pensamento político de um filósofo do século XVII cujo pensamento político costuma ser negligenciado pela Ciência Política.

O artigo de Juliane Helanski, então, permite ao mesmo tempo conhecer um pouco o contexto e biografia de Bento Espinosa - que nem sempre é considerado entre os clássicos da política - e explicitar “como" uma das elaboradoras do método realizou efetivamente a sua aplicação para situar um autor e sua obra no seu contexto social. Mostrou que nem todas as questões das sete tabelas foram respondidas - quer dizer, nem todos os aspectos que Neal Wood e Ellen Wood levantaram como relevantes para realizar uma história social da teoria política - precisam ser necessariamente respondidos a respeito de cada autor. Porém, mostrou que a leitura realizada por meio da contextualização social altera a compreensão que surge de uma abordagem meramente textualista, ainda que nem todas as questões sejam respondidas de modo exaustivo: Bento Espinosa pela ótica de Ellen Meiksins Wood é diferente do que foi apresentado por outras interpretações marxistas como as de Marilena Chaú e Antonio Negri.

O sexto artigo - A relevância do pensamento politico de Emma Goldman para a Ciência Política - apresenta uma reflexão que teve por base a pesquisa realizada por Francioli Bagatin para sua dissertação de mestrado (BAGATIN, 2018). Com o objetivo de analisar o pensamento político elaborado por mulheres, mostra que a anarquista Emma Goldman também produziu reflexões consistentes acerca de questões relevantes para a Ciência Política, tais como os conceitos de Estado, governo, política, poder e democracia. Assim como os autores clássicos eram engajados e isso não desmerece suas reflexões sobre a política, Emma Goldman merece figurar ao lado dos "clássicos" da política. Francioli Bagatin aplicou o método do contextualismo social - de Neal Wood e Ellen Meiksins Wood - explicitando que mesmo Emma Goldman sendo abertamente anarquista, feminista, ou seja, partidária no conflito do período, foi também uma "pensadora" da política cujas ideias estão organicamente ligadas ao contexto social em que viveu e escreveu.

O principal mérito do trabalho de Francioli Bagatin está em mostrar que, assim como os clássicos da política que foram considerados "neutros" por muitos comentadores - e, por isso, aparentemente teriam construído teorias políticas com maior grau de "objetividade" - tiveram sua neutralidade criticada por Neal Wood e Ellen Wood ao mostrarem que todos tinham algo de "ideológico" porque isso é uma das características da teoria política, o inverso também pode ser percebido: alguns autores e autoras que são abertamente partidários foram capazes de produzir reflexões sobre a política que não são apenas “ideológicas". Uma anarquista feminista, como Emma Goldman, além de se posicionar no conflito, foi capaz de produzir reflexões consistentes "para" fundamentar seu posicionamento político no conflito do 
período e seu pensamento político pode ser separado das prescrições ideológicas tanto no caso dos clássicos da política - tratados como autores "neutros" - como no dos autores e autoras que assumem abertamente um "posicionamento" político no conflito do período em que viveram.

No sétimo artigo - Como ler a obra "Introdução à Revolução Brasileira" de Nelson Werneck Sodré? Reflexões iniciais sobre a adoção do método textualista ou do contextualismo social - a professora Rosangela da Silva apresenta uma problematização a respeito do impacto que teria a escolha do método para o desenvolvimento de sua pesquisa de doutorado sobre um dos principais autores do pensamento social brasileiro. No artigo, conhecemos a tese de Nelson Werneck Sodré desenvolvida na obra "Introdução a Revolução Brasileira" (1958), ou seja, a ideia de que o Brasil vivenciava um processo revolucionário que teria como entraves "o imperialismo e os restos feudais ainda existentes em nossa sociedade" e como "agente" responsável por "dar cabo a este processo" a "classe média", sendo que a "burguesia nacional" contaria com o apoio de uma fração da "classe militar" - e o "rumo/direção" que a revolução deveria tomar no Brasil seria "pautado no nacionalismo e na manutenção e consolidação da democracia". Depois a autora questiona se a leitura dessa obra pode ser alterada pelo método escolhido.

A proposta do artigo é refletir sobre qual seria a forma mais adequada de conduzir a análise desta obra, pois se trata de um "projeto político para a sociedade brasileira". No artigo, discute os possíveis resultados ao utilizar três abordagens metodológicas distintas: (1) o textualismo a partir do pensamento de Léo Strauss, que propõe a leitura direta da obra, sem buscar referências externas; (2) o contextualismo linguístico proposto por Quentin Skinner, que propõe que se considere outras obras do período (para delinear o contexto intelectual) e um breve estudo do contexto histórico (para saber quais eram as questões relevantes que o autor queria responder); (3) o contextualismo social elaborado por Neal Wood e Ellen Meiksins Wood, que pretende situar meticulosamente autor e obra no contexto social (cultural, econômico e político). Apresenta e discute quais seriam os procedimentos realizados e que tipo de impacto teriam na compreensão dessa obra de Sodré, o que pode ser considerado relevante na leitura de outros autores brasileiros da mesma época ${ }^{5}$.

O oitavo artigo - O espectro da Lei de Bronze: a Teoria de Robert Michels como mecanismo de reflexão para a democracia representativa no século XXI - foi escrito em parceria por Jhonathan Matheus Dias, com base no seu trabalho de conclusão de curso de graduação em Ciências Sociais (DIAS, 2018), em parceria com seu orientador Geraldo Magella Neres. Mostra uma reflexão motivada pela metodologia do contextualismo social a respeito da teoria de um autor clássico da política cuja influência ainda é sentida nos estudos atuais. Além de ter estudado a principal obra de Robert Michels - Sociologia dos Partidos Politicos - Jhonathan Matheus Dias também abordou a crítica feita a ele por Antonio Gramsci e buscou analisar em que medida tais reflexões nos são úteis para compreender a realidade atual, valendo-se da parceria com seu orientador.

\footnotetext{
5 O artigo é exploratório a respeito das metodologias pois a autora ainda está realizando a pesquisa que irá fundamentar a construção de sua tese de doutorado, inspirada na sua participação nos encontros do GPDD.
} 
Como explicam os autores, a obra de Robert Michels foi publicada originalmente em alemão em 1911 e constitui um estudo feito com base na investigação empírica do Partido Socialdemocrata Alemão (SPD), por meio da qual Robert Michels construiu sua famosa "Lei de Bronze" da burocratização e oligarquização de "toda" organização social complexa. É interessante notar que mais de um século depois "o espectro da lei de bronze" ainda aparece nos debates a respeito das organizações humanas. O objetivo central do artigo é analisar a possibilidade de uso da teoria michelsiana de modo diferente do habitual que costuma ser um meio de justificação ao abandono do ideal democrático - já que toda organização complexa tenderia à elitização ou oligarquização (que são antidemocráticas). A proposta foi evidenciar o potencial da obra de Michels como um mecanismo de reflexão do complexo processo de formulação das instituições representativas no século XXI, por meio da aplicação do método do contextualismo social.

O nono artigo - Uma leitura de Verdade e Politica de Hannah Arendt: o contextualismo social altera o sentido da teoria política arendtiana? - resulta da parceria entre mim e a acadêmica Mariana da Silva Pereira condensando os principais resultados das pesquisas de iniciação científica e do trabalho de conclusão de curso que orientei (PEREIRA, 2018). Lembrando que o contextualismo social visa interpretar de forma mais substantiva e completa as ideias de teóricos da política, considerados "atores" políticos, engajados nos conflitos e problemas sociais da época e do lugar em que viveram, enfatizamos que a premissa dessa abordagem metodológica é de que não seria possível compreender adequadamente o significado de um texto de teoria política sem considerar o seu contexto social de produção, ou seja, além da análise textual - ou leitura direta das obras, seria necessário considerar aspectos ligados à biografia do autor, bem como a política, economia e cultura da sociedade em que a obra foi escrita.

O artigo apresenta uma aplicação do contextualismo social para a leitura de um ensaio escrito por Hannah Arendt - "Verdade e Política" (1967) - discutindo "se" isso realmente "altera" o entendimento a respeito do significado do texto (quando comparado com sua análise textualista, conforme propõe Leo Strauss). Ou seja, será que em comparação com a abordagem normativa, ou textualista, de leitura de textos clássicos da teoria política, seriam os resultados obtidos com a aplicação do contextualismo social diferentes a ponto de justificar o investimento na contextualização? De acordo com as autoras, embora existam vantagens no estudo da teoria política quando autor e obra são situados no contexto - social, econômico, político e cultural - da sociedade em que viveu e escreveu, no caso analisado, surgiram alguns questionamentos a respeito da imprescindibilidade da contextualização social para uma interpretação adequada da mensagem contida nesse ensaio de Hannah Arendt.

Em conjunto, os artigos apresentam vantagens e desvantagens do contextualismo social ao mesmo tempo que contribuem para a análise dos temas específicos a que se dedicaram as pesquisadoras e os pesquisadores envolvidos, concluindo uma etapa relevante do processo de pesquisa a que estivemos dedicados nos últimos anos no âmbito do Grupo de Pesquisa Democracia e Desenvolvimento. Com a publicação do Dossiê: Contextualismo Social, finalizamos uma importante etapa da pesquisa, apresentando os resultados obtidos para conhecimento da comunidade acadêmica. 


\section{Referências}

BAGATIN, Francioli. O pensamento político da anarquista Emma Goldman: uma contextualização social. 128f. 2018. Dissertação (Mestrado em Ciências Sociais) - Universidade Estadual do Oeste do Paraná, Toledo, 2018. Disponível em: < http://tede.unioeste.br/handle/tede/4028>.

DIAS, Jhonathan Matheus. O espectro da Lei de Bronze: a Teoria de Robert Michels como mecanismo de reflexão para a democracia representativa no século XXI. 2018. Monografia (Graduação em Ciências Sociais) - Universidade Estadual do Oeste do Paraná, Toledo, 2018. Orientador: Geraldo Magella Neres.

HELANSKI, Juliane. Contextualismo social na prática: a interpretação da teoria política de Bento Espinosa feita por Ellen Meiksins Wood. 161f. 2017. Dissertação (Mestrado em Ciências Sociais) -

Universidade Estadual do Oeste do Paraná, Toledo, 2017. Disponível em: < http://tede.unioeste.br/handle/tede/3209>.

LACOWICZ, Ellis Fernanda. Trabalho livre e escravidão em Atenas: O contraponto de Ellen Meiksins Wood ao viés antidemocrático dos clássicos Sócrates, Platão e Aristóteles. 102f. 2018. Dissertação (Mestrado em Ciências Sociais) - Universidade Estadual do Oeste do Paraná, Toledo, 2018. Disponível em: < http://tede.unioeste.br/handle/tede/4096>.

NASCIMENTO, Jefferson F. A redefinição do conceito de classe e suas implicações políticas: uma análise sobre Ellen Meiksins Wood. 166f. 2018. Dissertação (Mestrado em Ciências Sociais) Universidade Estadual do Oeste do Paraná, Toledo, 2018. Disponível em: < http://tede.unioeste.br/bitstream/tede/3451/2/Jefferson Nascimento 2018.pdf > .

NERES, Geraldo Maella; DROMBOWSKI, Osmir; SILVA, Vania Sandeleia Vaz da. A construção do conceito moderno de democracia: versão inicial de um projeto de pesquisa. Tempo da Ciência (UNIOESTE), v. 23, p. 98-115, 2016.

PEREIRA, Mariana da Silva. Verdade e Política: Diálogo entre as teorias de Hannah Arendt e Leo Strauss. 2018. Monografia (Graduação em Ciências Sociais) - Universidade Estadual do Oeste do Paraná, Toledo, 2018. Orientadora: Vania Sandeleia Vaz da Silva.

SILVA, Vania Sandeleia Vaz da Silva. O contextualismo social de Neal Wood e Ellen Meiksins Wood: uma introdução. Anais do V Simpósio Paranaense de Ciências Sociais. Disponível em: http://200.201.88.178/simposiocienciassociais/arquivos anais/ANAIS\%20SIMPOSIO \%20final.pdf\# page $=86 \&$ zoom $=100,109,269$ Acesso em: 05 out. 2019.

WOOD, Ellen Meiksins. Citizens to lords: A social history of Western Political Thought from Antiquity to the Middle Ages. London: Verso, 2008.

Liberty and Property: a Social History of Western Political Thought from Renaissance to Enlightenment. London: Verso, 2012 